\title{
Simulation for Solving Bottom-neck Problem in Light-soaked Divider Mechanic production line
}

\author{
Srisuwannapa C \\ School of Science, Mae Fah Luang University \\ (Received 30 December 2020; Accepted 28 May 2021) \\ DOI: https://doi.org/10.36224/ijes.140201
}

\begin{abstract}
The research objective is to find better solutions to solve problem of bottom-neck in production line of light-soaked Divider Mechanic of case study company producing promotional labels, price tag, floor sticker, Stand-up signage for indoor and outdoor use with a comprehensive printing style using system simulation with Arena software. The results were as follows. In case of production of 25 pieces/day, the best way to improve system efficiency is Scenario 4 , reducing the completion time of the system of down to $23.12 \%$, and Scenario 3 , reducing the system time of down to $22.91 \%$ consecutively. In case of production of 50 pieces/day, the best way to improve system efficiency is Scenario 3 , reducing the system completion time of down to $23.39 \%$ and then Scenario 4 , reducing the completion time of the system of down to $22.57 \%$ consecutively. In case of production of 100 pieces/day, the best way to improve system efficiency is Scenario 3, reducing the system completion time of down to $24.03 \%$. and then Scenario 4 , reducing the completion time of the system of down to $23.03 \%$ consecutively.
\end{abstract}

\section{Background and importance of the problem}

At present, the print media industry has adopted various technologies in the production process in order to improve the production process efficiency, deliver products on time, meet the needs of customers, build confidence and satisfaction. In2015, Wongsaichua. C., and et all, studied the process of analyzing waste by creating a stream valued mapping (VSM) using Arena to propose a concept of improving the production process of Frame sub ass'y seat support. They proposed 5 ways to improve the welding process such as adjusting the welding orientation (Scenario1), improving by adding ROBOT to the process with ROBOT2 (Scenario 2), improving by adding a task station (Scenario3), Improving by adding ROBOT to the welding process with ROBOT 1 and adding task stations (Scenario 4), and improving by adding ROBOTS to the welding process with ROBOT1 and ROBOT2 (Scenario 5). From results, it was found that number of products from Scenario 4 and 5 which is equally maximal is equal to 277 pieces/day from old number of 159 pieces. When considering the average waiting time and expenses over a period of 5 years, the average waiting time and cost for scenario 5 are less than others and equal to $6,855.98$ seconds decreased from old one of $11,192.76$ seconds or $38.75 \%$ and 3,813,680 Baht, consecutively. So, they suggested company's owners to improve the welding process by adding ROBOT in the welding process with ROBOT1 and ROBOT2.

This research case study operates in the field of design, production as order and installation of promotional labels, price tag, floor sticker, Stand-up signage for indoor and outdoor use with a comprehensive printing style. The sample factory was established in 2001, which has been operating for 17 years. It had different style of order and number in each period of time for which large amount of order has come in festival duration since their customers need these advertising labels to promote their products in this duration and in addition to, some works of some order require skilled employee, or some steps of production take long time to complete. These mention things make 
bottom-neck problem of production, then over time production including temporal employee were required necessarily since production were not on time as in normal working time (8.30-17.30).

Research team had studied only the production line of Divider Mechanic as light-soaked type due to the complex production processes that require production skills and lots of demand cause production problem using Arena for creating simulation model to find efficient Scenarios and decrease waste in production process of Divider Mechanic as light-soaked type.

\section{Research Objectives}

To propose guidelines for optimizing the production process, divider mechanic, light-soaked type.

\section{Scope of Research}

Study production process the $20 \times 100 \mathrm{~cm}$ divider mechanic of the sample factory as case study by studying only the manufacturing processes. The duration of this research is 4 months from January 8,2018to April 30, 2018.

\section{Operating Procedures}

The research consists of 7 steps as follows:

1) Study the general condition and process of case-study factory and define the topic of the problem to be studied.

2) Study related theories and literature

3) Collect time data of operations and production lines of divider mechanic only as the light-soaked type.

4) Analyze the import data distribution

5) Create and test accuracy of simulation model of production line of divider mechanic only the light-soaked type by comparing with the actual system using the Arenaprogram.

6) Conduct experiment various Scenarios.

7) Analyze the results from the simulation models and propose solutions.

\section{Production Process of Divider Mechanic in light-soaked type}

In Divider Mechanic process, it has 4 employees who specialize in producing this type of product for which employees will help each other complete in each process before proceeding to the next stage. This causes each process to have waiting times to occur. For detailed production steps as Arena format, the following are shown:

1) Create module, named "order arrives to system", created to determine volume of production order, for this research, having 3 volumes: 25,50 , and 100 pieces/day.

2) Batch Module used to determine Batch Size: 25, 50, and 100 pieces/day.

3) Process Module, named "get sticker", created to get all stickers used in total production.

4) Process Module, named "get acrylic", used to the receipt of acrylic sheet required in production.

5) Process Module, named "make block", used to create the mold used for the mount process.

6) Separate Module created to release each work in process to next steps of production.

7) Process Module named "sticker prep" used to prepare the required stickers for each workpiece.

8) Process Module, named "mount" used to mount sticker on acrylic sheet with mount machine and 2 employees.

9) Batch Module, named "Batch to Dicut Room", used to collect all workpieces after completing from mounting.

10) Process Module, named "Send to Dicut Room", used to send workpiece to Dicut room.

11) Separate Module, named "Separate for Dicut", used to release each workpieces to next steps. 
12) Process Module, named "Dicut pop up area", used to cut each workpiece.

13) Batch Module, named "Batch to production line", used to collect all workpieces after finishing di-cutting.

14) Process Module, named "send back", used to send all workpieces to production room.

15) Separate module, named "Separate to production line", used to releases the workpiece one by one to enter the next process.

16) Process Module, named "side B cutting", used to cut the edge of the excess sticker on the side A.

17) Process Module, name B cutting", used to cut the edge of excess sticker in side B.

18) Process Module, named "pop up prep", used to apply acrylic sheet for use as Popup

19) Process Module, named "rub and stick Hip", used to polish HIP lines with sandpaper to smooth and stick HIP lines on acrylic sheet side A.

20) Module Process, named "make frame", used to create structure of workpieces.

21) Process Module, named "drill and stick grid", used to drill the head and end of the workpiece, then insert the mesh into.

22) Process Module, named "stick wire", used to attach to the inner wire of the workpiece.

23) Process Module, named "assemble", used to assemble workpieces as box.

24) Process Module named "stick pop up" used to sticks popup onto the workpiece.

25) Process Module named "stick frame sticker and drill", used to attach a sticker on the side edge and cut the sticker over the sieve hole to vent the heat.

26) Dipose Module, named "finished goods" used to complete the process.

From the production process. The simulation system model in Arena format can be created as shown in Figure 1.

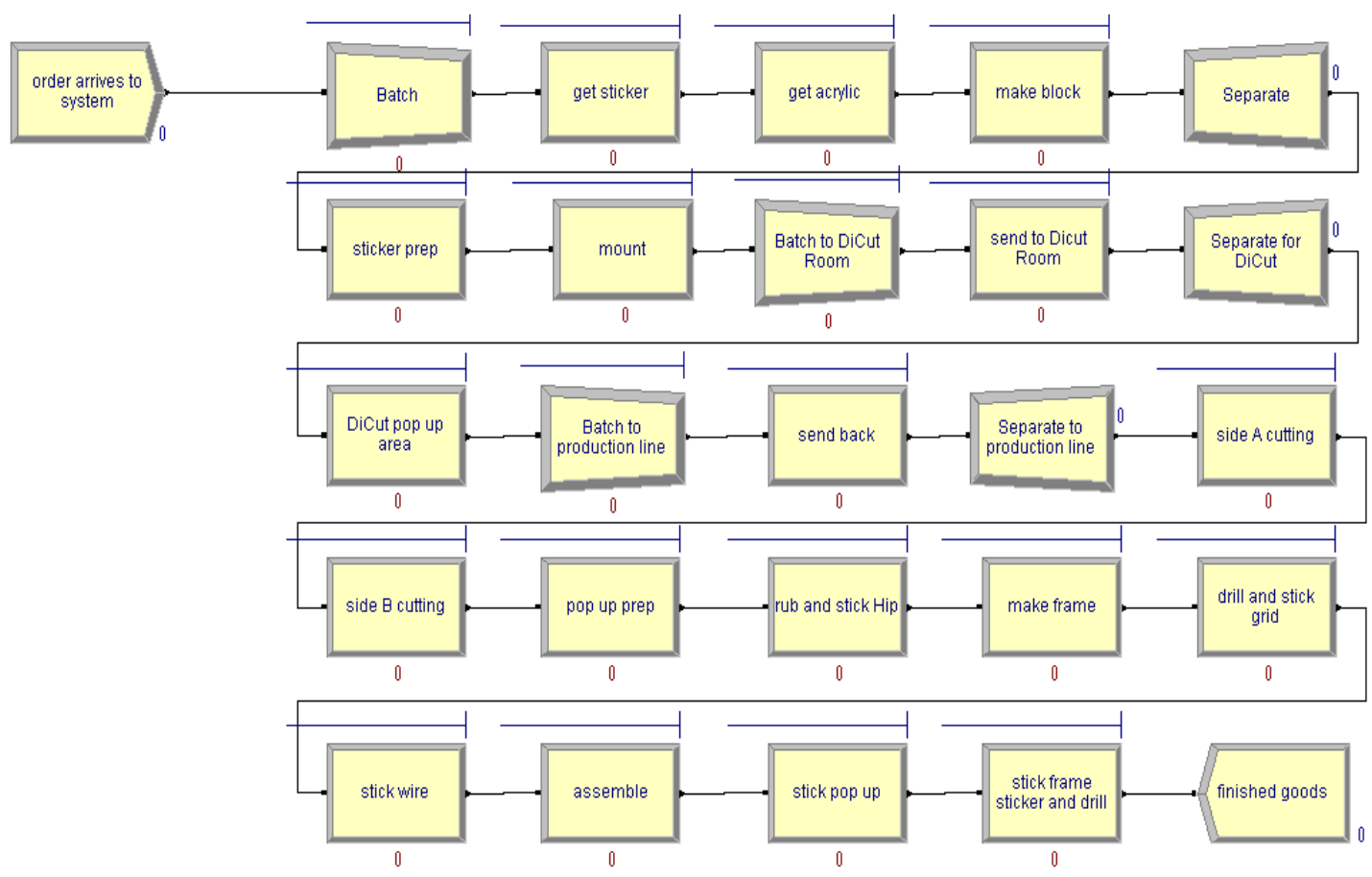

\section{Operation Results}

Figure 1: Divider Mechanic as the light-soaked type.

\subsection{Input data analysis}

Displays the analysis of the distribution of time on each process step as table 1.

Table 1:Distribution of time data in the production process. 


\begin{tabular}{|l|l|l|l|}
\hline Step & N & p-value & Distribution \\
\hline Background's mount & 30 & 0.365 & NORMAL $(153,7.41)$ \\
\hline To slit the edges & 30 & 0.726 & UNIF $(102,158)$ \\
\hline Popup Preparation & 25 & More than 0.15 & $\begin{array}{l}\text { TRIA }(1.34 \text { and }+003,1.41 \text { and }+003,1.76 \text { and }+003) \\
, 1\end{array}$ \\
\hline $\begin{array}{l}\text { Polishing \& Sticking Hip } \\
\text { Lines }\end{array}$ & 30 & More than 0.75 & POIS $(130)$ \\
\hline Building the frame. & 30 & More than 0.15 & $1.2 \mathrm{e}+003+127 *$ BETA(1.68,1.19) \\
\hline Drill hole and grating & 30 & More than 0.15 & $366+142^{*} \operatorname{BETA}(1.4,1.63)$ \\
\hline Attach the electricalwire. & 30 & 0.0935 & $113+55^{*} \operatorname{BETA}(1.26,1.09)$ \\
\hline Assemble & 30 & More than 0.15 & $\mathrm{UNIF}(378,523)$ \\
\hline Attaching Popup & 25 & More than 0.15 & $\mathrm{UNIF}(853,1.74 \mathrm{e}+003)$ \\
\hline $\begin{array}{l}\text { Put stickers on the side } \\
\text { edges and drill holes. }\end{array}$ & 30 & More than 0.15 & $\mathrm{UNIF}(973,1.45 \mathrm{e}+003)$ \\
\hline
\end{tabular}

6.2. Validation of the simulation model as system's representative of the production line of Divider Mechanic as Light-Soaked Type

When the current simulation model is created, it is necessary to verify the accuracy between the actual system and the current representative simulation model, using the operating time and system completion time data, compared to the actual system value as in table 2.

Table 2: Comparing differences and percentages of differences between the actual system and the current representative simulation model of different processes. In the divider mechanic production line only as the light is soaked by repeating 30 times of simulation runs

\begin{tabular}{|l|l|l|l|l|}
\hline \multirow{2}{*}{ Step By Step } & \multicolumn{2}{|l|}{ Average time(seconds) } & \multirow{2}{*}{ Difference } & $\begin{array}{l}\text { \% } \\
\text { Difference }\end{array}$ \\
\cline { 2 - 3 } & Actual value & Models & & 153.36 \\
\hline Background's mount & 153 & 0.36 & 0.24 \\
\hline To slit the edges & 129.27 & 130.42 & 1.15 & 0.89 \\
\hline Popup Preparation & 129.27 & 129.24 & 0.03 & 0.02 \\
\hline Polishing \& Sticking Hip Lines & 1501.68 & 1503.26 & 1.58 & 0.11 \\
\hline Building the frame & 130.27 & 130.44 & 0.17 & 0.13 \\
\hline Drill hole and grating & 1270.40 & 1275.68 & 5.28 & 0.42 \\
\hline Attach the electrical wire. & 431.67 & 431.73 & 0.06 & 0.01 \\
\hline Assemble & 141.93 & 142.36 & 0.43 & 0.30 \\
\hline Attaching Popup & 449.90 & 451.48 & 1.58 & 0.35 \\
\hline $\begin{array}{l}\text { Put stickers on the side edges and } \\
\text { drill holes. }\end{array}$ & 1297.60 & 1292.45 & 5.15 & 0.40 \\
\hline Background's mount & 1203.10 & 1208.2 & 5.10 & 0.42 \\
\hline
\end{tabular}

From Table 2. The difference percentage between the actual system and the simulation model was found not more than 10\% (Wongsaichua, $C$ et.all. 2018). Therefore, the simulation model can represent the actual system and then can bring to experiment in many Scenarios later.

\subsection{How to Improve Production line of Divider Mechanic only as Light-Soaked Type}

There are 4 ways to improve problem of bottom-neck that make production discontinuing and delay as follows:

1) Alternative 1 (Scenario 1): Adding 1 employee to be 5 ones. 
2) Alternative 2 (Scenario 2):Adding 1 mount machine and 1 dicut machine to be 2 mount machines and 2 dicut machines.

3) Alternative 3 (Scenario 3): Adding 1 employee to be 5 ones and adding 1 mount machine and 1 dicut machine to be 2 mount machines and 2 dicut machines.

4) Workaround 4 (Scenario 4): Adding2 employee 2 to be 6 employees.

\subsection{Resultsfrom Improving the Light-soaked Divider Mechanic production line}

In experimenting each 4 Scenarios, 100 simulation runs for each Scenario were made and their results as follows.

Based on the results of the experiment shown in Table 3. In case of production of 25 pieces/day, for Scenario, it can reduce the system completion time of down to $14.43 \%$. Scenario 2, it can reduce the system completion time of only $8.48 \%$. Scenario 3, reducing the system completion time of down to $22.91 \%$. Scenario 4,reducing the completion time of the system of down to $23.12 \%$ as shown below.

Based on the results of the experiment shown in Table 4. In case of production of 50 pieces/day, for Scenario 1, it can reduce the system completion time of down to $13.39 \%$. Scenario 2, it can reduce the system completion time of only $10.00 \%$. Scenario 3, reducing the system completion time of down to $23.39 \%$. Scenario 4, reducing the completion time of the system of down to $22.57 \%$ as shown below.

Based on the results of the experiment shown in Table 5. In case of production of 100 pieces/day, for Scenario 1, it can reduce the system completion time of down to $13.80 \%$. Scenario 2, it can reduce the system completion time of only $10.24 \%$. Scenario 3, reducing the system completion time of down to $24.03 \%$. Scenario 4, reducing the completion time of the system of down to $23.03 \%$ as shown below.

Table 3: Completion time, percentage of time differences between the original and simulation model when 25 pieces were produced pay day

\begin{tabular}{|l|l|l|l|l|l|l|l|l|l|}
\hline & $\begin{array}{l}\text { Original } \\
(\mathrm{O})\end{array}$ & \multicolumn{2}{|l|}{ Scenario 1 (S1) } & \multicolumn{2}{l|}{ Scenario 2 (S2) } & \multicolumn{2}{l|}{ Scenario 3 (S3) } & \multicolumn{2}{l|}{ Scenario 4 (S4) } \\
\cline { 2 - 9 } Step & $\begin{array}{l}\text { Time } \\
\text { (seconds) }\end{array}$ & $\begin{array}{l}\text { Time } \\
\text { (seconds) }\end{array}$ & $\begin{array}{l}\text { \% } \\
\text { difference } \\
\text { of O with } \\
\text { S1 }\end{array}$ & $\begin{array}{l}\text { Time } \\
\text { (seconds) }\end{array}$ & $\begin{array}{l}\text { \% } \\
\text { difference } \\
\text { of O with } \\
\text { S2 }\end{array}$ & $\begin{array}{l}\text { Time } \\
\text { (seconds) }\end{array}$ & $\begin{array}{l}\text { \% } \\
\text { difference } \\
\text { with S3 }\end{array}$ & $\begin{array}{l}\text { Time } \\
\text { (seconds) }\end{array}$ & $\begin{array}{l}\text { Difference } \\
\text { of O } \\
\text { sith }\end{array}$ \\
\hline $\begin{array}{l}\text { System } \\
\text { completion } \\
\text { time }\end{array}$ & $64,334.88$ & $55,052.89$ & 14.43 & $58,878.24$ & 8.48 & $49,596.25$ & 22.91 & $49,462.73$ & 23.12 \\
\hline
\end{tabular}

Table 4: Completion time, percentage of time differences between the original and simulation model when 50 pieces were produced pay day.

\begin{tabular}{|l|l|l|l|l|l|l|l|l|l|l|}
\hline \multirow{2}{*}{ Step By Step } & Original (O) & \multicolumn{2}{|l|}{ Scenario 1 (S1) } & \multicolumn{2}{l|}{ Scenario 2 (S2) } & \multicolumn{2}{l|}{ Scenario 3 (S3) } & \multicolumn{2}{l|}{ Scenario 4 (S4) } \\
\cline { 2 - 10 } & $\begin{array}{l}\text { Time } \\
\text { (seconds) }\end{array}$ & $\begin{array}{l}\text { Time } \\
\text { (seconds) }\end{array}$ & $\begin{array}{l}\% \text { O } \\
\text { difference } \\
\text { of O with } \\
\text { S1 }\end{array}$ & $\begin{array}{l}\text { Time } \\
\text { (seconds) }\end{array}$ & $\begin{array}{l}\% \text { O } \\
\text { difference } \\
\text { with S2 }\end{array}$ & $\begin{array}{l}\text { Time } \\
\text { (seconds) }\end{array}$ & $\begin{array}{l}\text { O } \\
\text { difference } \\
\text { of O with } \\
\text { S3 }\end{array}$ & $\begin{array}{l}\text { Time } \\
\text { (seconds) }\end{array}$ & $\begin{array}{l}\text { O } \\
\text { difference } \\
\text { of O with } \\
\text { S4 }\end{array}$ \\
\hline System completion time & $113,048.20$ & 97911.72 & 13.39 & 101741.73 & 10.00 & 86605.24 & 23.39 & 87529.45 & 22.57 \\
\hline
\end{tabular}


Table 5: Completion time, percentage of time differences between the original and simulation model when 100 pieces were produced pay day

\begin{tabular}{|l|l|l|l|l|l|l|l|l|}
\hline & Original (O) & \multicolumn{2}{|l|}{ Scenario 1 (S1) } & \multicolumn{2}{l|}{ Scenario 2 (S2) } & \multicolumn{2}{|l|}{ Scenario 3 (S3) } & \multicolumn{2}{l|}{ Scenario 4 (S4) } \\
\cline { 2 - 9 } Step By Step & $\begin{array}{l}\text { Time } \\
\text { (seconds) }\end{array}$ & $\begin{array}{l}\text { Time } \\
\text { (seconds) }\end{array}$ & $\begin{array}{l}\% \text { O } \\
\text { difference } \\
\text { with S1 }\end{array}$ & $\begin{array}{l}\text { Time } \\
\text { (seconds) }\end{array}$ & $\begin{array}{l}\% \text { Tifference } \\
\text { with S2 }\end{array}$ & $\begin{array}{l}\text { Time } \\
\text { (seconds) }\end{array}$ & $\begin{array}{l}\text { O } \\
\text { difference } \\
\text { with S3 }\end{array}$ & $\begin{array}{l}\text { Time } \\
\text { (seconds) }\end{array}$ \\
$\begin{array}{l}\text { System } \\
\text { difference } \\
\text { with S4 }\end{array}$ \\
\hline
\end{tabular}

\section{Summary}

In case of production of 25 pieces/day, the best way to improve system efficiency is Scenario 4 , reducing the completion time of the system of down to $23.12 \%$, and Scenario 3, reducing the system completion time of down to $22.91 \%$ consecutively.

In case of production of 50 pieces/day, the best way to improve system efficiency is Scenario 3 , reducing the system completion time of down to $23.39 \%$ and then Scenario 4 , reducing the completion time of the system of down to $22.57 \%$ consecutively.

In case of production of 100 pieces/day, the best way to improve system efficiency is Scenario 3, reducing the system completion time of down to $24.03 \%$. and then Scenario 4 , reducing the completion time of the system of down to $23.03 \%$ consecutively.

\section{References}

[1] Sukwattana, K., (2008) Development and Improvement of Production to Increasing Products. Case Study: Electronics Factory. Presenting to Engineering Faculty, Thammasat University.

[2] Wongsaichua, C et,al., (2518). Improving Production Line of Frame sub ass'y seat support: Case Study: Thai Summit Gold Press, 1td., Presenting to Faculty of Science, King Mong Kut' Institute of Technology Ladkrabang.

[3] Pisanpen, R. (2008). Manual of Creating Simulation Model using Arean. Bangkok: C Education comp. ltd press.

[4] Jerry B. and John S.C. (1984) Discrete-Event System Simulation. 2nd ed. New Jersey: Prentice-Hill.

[5] Pegden C.D., Shannon R.E. and Sadowski R.P. (1995). Introduction to Simulation Using Siman. New York: McGraw-Hill. 